\title{
JORGE LUIS BORGES Y LA OTREDAD INQUIETANTE
}

\author{
Karen Poe Lang
}

\begin{abstract}
RESUMEN
Este ensayo ha sido estructurado a partir de la consigna de meditar las posibles relaciones entre filosofía y literatura desde la escritura de Jorge Luis Borges. Propongo que la lectura del texto filosófico, entre otros, le permitió al autor argentino adelantarse casi 30 años a las postulaciones de la teoría literaria postestructuralista. A partir de la lectura de Discusión libro que recoge ensayos escritos entre 1928 y 1932, intento probar que los conceptos de texto, intertextualidad y el binomio lectura/escritura ya estaban presentes en la visión borgeana de la literatura.

Palabras clave: Postestructuralimo, Borges/Barthes, teoría del texto, intertextualidad.
\end{abstract}

\begin{abstract}
The purpose of this article is to examine the relation between literature and philosophy, inside Jorge Luis Borge's writings. I propose that the way in which Borges read's the philosophical text, among other texts, was an essential condition of his literary theory. From a close reading of Discusion (book formed with texts written between 1928 and 1932) it is possible to prove that the main ideas of poststructural literary criticism -text, intertextuality, to read/to write- were theorized very early by Borges.
\end{abstract}

Key words: Postestructuralism, Borges/Barthes, Theory of the text, Intertextuality.

\section{Introducción}

Cuenta María Esther Vázquez en su biografía de Borges que, durante el verano, el escritor y sus padres solían pasar temporadas en el Hotel Las Delicias de Adrogué, pequeña localidad al sur de Buenos Aires

\footnotetext{
Borges recordaba que a la noche, después de comer, salían a caminar por las calles tranquilas y olorosas de madreselvas, ligustrinas y jazmines en flor: Tratábamos de perdernos, a veces lo lográbamos o nos decíamos creo que nos hemos perdido, poniendo la más buena voluntad por hacerlo en aquel tranquilo laberinto (1996: 144).
}

\footnotetext{
Karen Poe Lang. Catedrática de la Escuela de Estudios Generales, Universidad de Costa Rica. Correo electrónico: ayarco@ice.co.cr
}

Recepción: 10- 12- 2007

Aceptación: 7- 1- 2008 
He comenzado esta exposición haciendo referencia a la extraña costumbre de la familia Borges de salir a caminar por la noche con la secreta intención de extraviarse, porque, en alguna medida, quisiera que mi acercamiento al universo borgeano recuperara el misterio de la caminata nocturna, el olor de la ciudad sin prisa -cuando aún había tiempo que perder-, el estilo lento y digresivo de la conversación. Me perdonarán, entonces, que no haga una exposición sistemática, pues como decía Borges (1980: 416) "un sistema no es otra cosa que la subordinación de todos los aspectos del universo a uno cualquiera de ellos". Lejos de la disertación filosófica, materia que por lo demás no es mi oficio, les propongo un recorrido guiado, más que por la linealidad del pensamiento, por el asombro y el gozo experimentados ante la escritura de Borges. Ese será el juego, y el placer.

\section{Desvío}

Pero antes, un desvío. Este trabajo ha sido estructurado a partir de la consigna de meditar las posibles relaciones entre filosofía y literatura. Dada la complejidad de este campo he preferido limitarme a un escritor particular: Jorge Luis Borges, quien fue un lector apasionado del texto filosófico.

Quisiera, además, hacer algunas precisiones. Lejos de una postura interdisciplinaria -que parte del prejuicio según el cual las disciplinas han tajadeado malamente parcelas de un supuesto saber global que, por lo tanto, se ven en la obligación de unificar- intentaré perseguir la resonancia que ciertos problemas, surgidos en el seno de la filosofía, han tenido en la obra de Borges. De más está decir que nuestro autor nunca pretendió hacer filosofía y supo que su destino era, inevitablemente, literario.

La relación de Borges con la filosofía dibuja un trayecto de ida y vuelta, circular, mas no recíproco, tampoco complementario. Borges no complementa la filosofía, la desquicia, la obliga a pensarse más allá de sus propios límites.

Tenemos noticia, al menos, de un gran efecto de la escritura de Borges en el campo de la filosofía. En 1966, Michel Foucault publica Las palabras y las cosas, escrito que provoca, en el medio intelectual francés, una virulenta polémica. Su autor declara en el prefacio:

Este libro nació de un texto de Borges. De la risa que sacude, al leerlo. Todo lo familiar al pensamiento -al nuestro: al que tiene nuestra edad y nuestra geografía-, trastornando todas las superficies ordenadas y todos los planos que ajustan la abundancia de seres, provocando una larga vacilación e inquietud en nuestra práctica milenaria de lo mismo y de lo otro (1984: 1).

¿Adónde nos conduce la risa de Foucault? ¿Cómo interpelará la escritura de Borges a los filósofos contemporáneos? Dejo en el aire estas preguntas, ya que por ahora nuestro recorrido irá en sentido inverso.

Intentaré rastrear los efectos de lectura que algunas problematizaciones centrales del discurso filosófico han provocado en el texto borgeano. Mi propósito no es seguir las huellas de algunos filósofos como Platón, Berkeley, Hume, Schopenhauer o Nietzche, al interior del texto de Borges. Esta es la vía por la cual discurre el libro de Juan Nuño La filosofía de Borges. El autor, luego de realizar una minuciosa búsqueda de las ideas filosóficas que cruzan sus escritos, propone la tesis de que su literatura, si bien se enmarca en el idealismo, opera en este una inversión. Recupero sus argumentos pues sugieren un rasgo predominante del modo en que Borges lee y, me atrevo a decir, deconstruye el texto filosófico:

La inversión llevada a cabo no ha podido ser más insolente: no son los eternos Arquetipos, comenzando por la poderosa Unidad, los que en sucesivas emanaciones crean todo, sino que es el hombre, una de 
las ínfimas emanaciones materiales, quien crea la eternidad a fuerza de suspirar imposibles o idealizar recuerdos (Nuño 1986: 119).

Plantear que la eternidad es creada a partir de suspiros e idealizaciones efectivamente pervierte el idealismo platónico y lo baña en un escepticismo radical, cargado de imposibilidades. Esta manera de leer el texto filosófico, invirtiendo los valores, será una constante en el devenir del pensamiento borgeano.

\section{Borges lector-escritor}

Creo vislumbrar que la lectura del texto filosófico, tal y como la practica Borges, constituye una marca indeleble de su escritura, por lo menos en dos aspectos: su modo lúdico de asumir la reflexión teórica y su estilo. Hay una tensión constante en el estilo de Borges que oscila entre la lucidez intelectual y el juego irreverente. Algunos críticos han señalado el uso frecuente del paréntesis en su escritura como una estrategia de su pensamiento que constantemente se ve llevado a precisar, a matizar e incluso a contradecir sus afirmaciones. Este rasgo elemental de su estilo se convierte en una táctica desestructuradora que pone a bailar los sentidos en ritmos muchas veces disonantes.

Cuentan sus biógrafos que cuando Borges cumplió siete años, su padre, un intelectual librepensador, consideró que era el momento de introducirlo en la lectura de Platón. Acaso se deba a esta temprana lectura del filósofo griego el tono desprejuiciado con que Borges asume el pensamiento filosófico. No es difícil imaginar los efectos mágicos que pudo tener el mito de la caverna sobre los sueños y las fantasías de un niño que apenas, como plantean los psicólogos, entraba en la edad del pensamiento racional.

A Borges, con su característica irreverencia, le encantaba decir que la filosofía era una rama de la literatura fantástica. Además, afirmaba que su estimación por las ideas filosóficas no estaba determinada por su verdad, sino por su valor estético, por lo que encerraban de singular y maravilloso. Ana María Barrenechea en su ya clásico libro La expresión de la irrealidad en la obra de Borges hace una enumeración ilustrativa de las opiniones del autor en relación con las ideas filosóficas. La cito a continuación:

\footnotetext{
...(a Borges) le atrae la dificultad de precisar la dirección del tiempo por hermosa, la eternidad de Ireneo y la de Platón por sencillas y mágicas, la tesis de Gosse por su elegancia un poco monstruosa y por ingeniosa e increíble, las teorías de Dunne le parecen tan espléndidas que les perdona sus inconsistencias y sus errores, el eterno retorno es una elegante esperanza, su admiración por Heráclito se debe al hallazgo metafórico del río y en Zenón de Elea lo admiran los inmortales antagonistas (1984: 61).
}

Su interés por la filosofía privilegia el estilo, la elegancia, la hermosura, la sencillez. Pero no solamente. Borges también importa $^{1}$ las problematizaciones que han surgido en el campo filosófico y estas se convierten en motor de su trabajo. Cuando apela a los grandes temas filosóficos es para deformarlos. En su pluma, el problema del infinito puede derivar en la trama de un cuento o darle consistencia a unos personajes. Hábil lector de las paradojas eleáticas (a las que llama pedacitos de tiniebla griega), estas, más que un tema recurrente en sus cuentos y ensayos, constituyen un modo de proceder de su escritura, que la crítica no deja de calificar como paradójica.

Si bien las obsesiones de su discurso no cesan de convocar problemas que han surgido en el campo filosófico, ante la certeza de que sus textos no son más que ficciones, Borges no vacila en conducir el pensamiento hacia el abismo de la multiplicidad y la diseminación. 
Lo anterior es posible gracias a un modo especial de leer. Como plantea Rafael Olea, ya desde sus primeras letras, Borges entendía la vanguardia no tanto como una práctica escritural, sino como un modo de leer, que implicaba una reformulación de las tradiciones y una actitud de rechazo de las jerarquías y los valores consagrados. Sigamos su planteamiento:

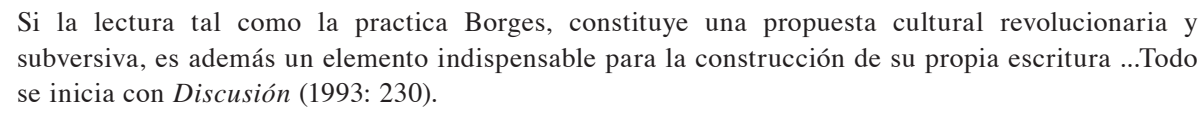

Discusión es precisamente el texto que quiero explorar centralmente en este escrito.

\section{Un primer asombro}

Un primer asombro invade al lector de Discusión, libro en el cual se agrupan ensayos que -exceptuando el texto "El escritor argentino y la tradición”, escrito en la década del 40- fueron publicados entre 1928 y 1932. En sus páginas Borges reflexiona incisivamente sobre los procedimientos y recursos de la escritura, medita sobre la escabrosa relación entre el lenguaje y la realidad, problematiza los avatares de la estética. El tono es sencillo, alejado de tecnicismos, casi acogedor, sin por eso dejar de ser irónico. Borges (1999: 83) decía que su amigo Macedonio Fernández -a quien admiraba profundamente- "cometía el error generoso de atribuir su inteligencia a todos los hombres". También Borges generosamente atribuye a su lector la brillantez de su inteligencia, y, más aún, su sabiduría. Como dice Ana María Barrenechea "hay una cierta cortesía en la manera de escribir de Borges, como si no quisiera imponer al lector sus ideas".

Pero volvamos a Discusión. ¿Cuál es el motivo de nuestro asombro? Creo que a nosotros -lectores nacidos en los años 60- habituados al tono poético de la crítica literaria postestructuralista, a las libertades del deconstruccionismo y sobre todo a su complejidad teórica y terminológica, nos impacta la lucidez inaugural del pensamiento de Borges. Al leerlo, nos cuesta creer que sus textos fueron escritos en 1932. Casi podemos escuchar a Barthes en alguna frase, o entrever a Derrida en sus inagotables estrategias de lectura. Pues en Borges están articulados los grandes conceptos que propiciaron, a fines de los 60, la revitalización del pensamiento alrededor del grupo Tel Quel. La intertextualidad, el concepto revolucionario de texto, las relaciones lectura-escritura, el autor y su muerte, el lector y sus trampas, emergen en sus escritos, sutilmente, sin énfasis. Como si pertenecieran a una tradición del pensamiento y, por lo tanto, no necesitaran introducción. Es más, Borges realiza, quizá sin proponérselo, uno de los mayores anhelos de los pensadores postestructuralistas: plantear una teoría sin necesidad de recurrir a un metalenguaje.

En Borges aparecen los conceptos, mas no siempre sus nombres. Tuvieron que pasar treinta años, el estructuralismo, las revueltas estudiantiles, la relectura de Freud por Lacan, y (¿por qué no?) la lectura del texto borgeano, para que los conceptos de Borges, a miles de kilómetros de distancia, encontraran sus nombres. La excepción fue la definición de texto, donde Borges, sorprendentemente, encuentra el nombre además del concepto.

En esta línea, comparto (no sin algunas objeciones) la opinión de Lillian Manzor Coats a quien me permito citar: 
Podría decirse que Jorge Luis Borges y Macedonio Fernández comienzan la empresa deconstructora... Sin hablar de influencias -concepto que de todas maneras, no tiene cabida dentro del discurso crítico posmoderno- está claro que el código literario de la posmodernidad tiene su origen en Hispanoamérica y que más tarde va a ser reinventado casi simultáneamente en otros lugares. A pesar de que este nuevo corpus literario latinoamericano es traducido al inglés y al francés desde los años 50, esta escritura revolucionaria ha sido marginada, salvo raras excepciones, por la crítica literaria (1996: 26- 27).

Me parece necesario matizar la idea de un posible origen hispanoamericano del código literario de la posmodernidad, ya que la idea misma de origen sería rechazada por Borges y, además, porque es innegable la contundencia con que el texto borgeano se encuentra incluido de manera intertextual en las tradiciones literarias, filosóficas y científicas europea y norteamericana. Lo cierto es que este hecho no disminuye nuestro asombro al leerlo.

Más adelante, la autora mencionada señala que, si bien los escritores europeos y norteamericanos han aprendido a convivir y apreciar la literatura hispanoamericana, la crítica literaria, en tanto centro de poder y legitimación, ha mantenido a nuestros escritores, fuera de su tradición, salvo contadas excepciones. En mi opinión este es un tema sumamente complejo y creo que la explicación anterior es insuficiente.

Me arriesgo a formular una hipótesis. Evidentemente, Borges es un ensayista que se adelanta a su época. Sus textos requieren un lector que en la década de los 30 aún no ha nacido. Son precisamente sus textos los que ayudarán a producir este nuevo lector.

¿Por qué no pensar el silencio de la teoría y la crítica literarias ante el texto borgeano como una incapacidad de lectura? Si nos ubicamos en la corriente postestructuralista, ¿cómo no ver que un texto necesita de su lector, activo y competente para darle vida?

Al parecer ya en su ensayo de 1930, "La supersticiosa ética del lector”, Borges deseaba este nuevo lector. Después de hacer una crítica a la lectura supuestamente ética dice lo siguiente:

\footnotetext{
Ahora quiero acordarme del porvenir y no del pasado. Ya se practica la lectura en silencio, síntoma venturoso. Ya hay un lector callado de versos (...)

Ignoro si la música sabe despertar de la música y si el mármol del mármol, pero la literatura es un arte que sabe profetizar aquel tiempo en que habrá enmudecido, y encarnizarse con la propia virtud y enamorarse de la propia disolución y cortejar su fin (1980: 138).
}

Curiosamente -al imaginar su nuevo lector habitado de silencio- Borges es obligado a pensar el enmudecimiento y la disolución de un cierto universo literario. Más adelante, y en relación con el tema de la lectura, volveré sobre la importancia del silencio en la poética borgeana. Antes quisiera retomar unas palabras de Jean Francois Lyotard pues nos ayudarán a pensar el destiempo entre el texto borgeano y su lector en la década del 30:

\footnotetext{
Un artista o escritor posmoderno está en la posición de un filósofo: el texto que escribe, la obra que produce no están gobernados en principio, por reglas preestablecidas, y no pueden ser juzgados de acuerdo a un juicio determinante aplicando categorías familiares al texto o la obra. Esas reglas y categorías es lo que la obra de arte busca. El artista y el escritor, entonces trabajan sin reglas para formular las reglas de lo que habrá sido hecho [citado por Manzor 1996: 32].
}

De esta forma el lector borgeano es un efecto de la lectura y relectura de su texto. La escritura de Borges es posmoderna en la medida que reformula las reglas de su campo y deja a sus lectores contemporáneos sin categorías familiares para juzgarlo, para hacerlo trabajar y ponerlo en movimiento. 


\section{Borges... Barthes... Borges}

Antes de continuar quisiera hacer otra precisión. Como el postestructuralismo ${ }^{2}$ es un término de límites difusos, que cobija a muchos autores cuyas diferencias no son para nada desdeñables, intentaré establecer un diálogo entre el texto de Borges y el de Roland Barthes. Me fundamento en el hecho de que el escritor francés ha sido convertido casi en símbolo de esta corriente.

Volvamos ahora a Discusión. Ya desde este libro se insinúa una postura iconoclasta en cuanto a tres problemas teóricos fundamentales: la relación entre la realidad y la ficción, el lugar del sujeto en la escritura y la literatura pensada como un trabajo sobre el lenguaje.

Si hacemos un repaso a los títulos que componen el volumen es evidente que dos campos del saber ocupan su atención. Un primer ámbito es la reflexión sobre el quehacer literario, manifiesto por ejemplo en los ensayos: "La poesía gauchesca", "El otro Whitman", "El arte narrativo y la magia", "La supersticiosa ética del lector", "Paul Groussac", "Flaubert y su destino ejemplar" y "Las versiones homéricas". El otro espacio lo constituyen las meditaciones filosóficas en los textos: "La penúltima versión de la realidad", "La perpetua carrera de Aquiles y la tortuga" y "Avatares de la tortuga". Mención aparte merece su ensayo "La postulación de la realidad", en el cual, a pesar de las connotaciones filosóficas del título, podemos observar cómo es que va surgiendo, precisamente a partir de la tensión que genera el diálogo entre literatura y filosofía, el novedoso pensamiento de Borges.

Y no es que Borges aplique mecánicamente ciertos conceptos filosóficos a su incipiente teoría literaria. Los problemas (más que los conceptos) filosóficos actúan en su escritura como una otredad inquietante y fascinante que le aporta un lugar excéntrico desde el cual pensar la literatura. Mi propuesta es que Borges arriba tan tempranamente a una teoría literaria -que tranquilamente podemos llamar postestructuralista- gracias a la forma en que pone a trabajar sus lecturas filosóficas al interior de su práctica escritural. Estas lecturas filosóficas (indudablemente en relación intertextual con sus lecturas literarias y científicas) constituyen un impulso irrefrenable en el decurso de su pensamiento.

Les propongo que sigamos los planteamientos de su ensayo "Las versiones homéricas" incluido en Discusión y en el cual problematiza el tema de la traducción. No parece mera casualidad el hecho de que Borges recurre precisamente a un filósofo, para deslizar su noción de texto

Bertrand Russell define un objeto externo como un sistema circular, irradiante, de impresiones posibles;

lo mismo puede aseverarse de un texto, dadas las repercusiones incalculables de lo verbal (1980: 181).

Llama la atención, aparte de la forma en que se apropia del pensamiento del filósofo, el empleo de la palabra texto en lugar de obra. Es como si el gusto manifiesto de Borges por el uso de las palabras en su significación primigenia, generalmente oculta por el uso, lo llevara a encontrar el concepto clave de la teoría literaria postestructuralista. Se sabe que Borges, al igual que las teorías del texto, buscaba alejarse de la visión romántica de la literatura. Su crítica era especialmente filosa en torno al concepto de hombre y a la forma en que ese movimiento entendía el problema de la creación artística, como un producto de la inspiración.

También es notable que Borges piense el texto como un sistema irradiante de impresiones posibles, es decir, como un espacio abierto, de repercusiones incalculables. Este concepto de texto encontrará su plena madurez en una conferencia de 1997 que Borges titula La poesía y en la cual dice: 
(...) mientras no abrimos un libro, ese libro, literalmente, geométricamente es un volumen, una cosa entre las cosas. Cuando lo abrimos, cuando el libro da con su lector, ocurre el hecho estético. Y aun para el mismo lector el mismo libro cambia, cabe agregar, ya que cambiamos, ya que somos (para volver a mi cita predilecta) el río de Heráclito, quién dijo que el hombre de ayer no es el de hoy y el de hoy no será el de mañana. Cambiamos incesantemente y es dable afirmar que cada lectura de un libro, que cada relectura, cada recuerdo de esa lectura, renuevan el texto. También el texto es el cambiante río de Heráclito (1993: 101- 102).

Señalo nuevamente el papel protagónico que juega el intertexto filosófico en la escritura de Borges. Tanto el lector como el texto son el río de Heráclito. Pienso que Barthes hubiera firmado gustoso esta afirmación. Al leer a Borges, no podemos no pensar en el deslizamiento terminológico efectuado por el postestructuralismo, que ante la noción romántica de obra -entendida como espacio cerrado y determinado por la intencionalidad y la expresividad del autor- opone el concepto de texto como lugar de múltiples relaciones, como espacio abierto, a la deriva, carente de la garantía de un sentido previo. Pero volvamos a Discusión.

Borges, quien ejerció con insistencia el modesto oficio de traductor, se propone liberarlo del pesado fardo del texto original. Comienza por declarar que la traducción parece destinada a ilustrar idóneamente la discusión estética. Pero su argumentación rebasa los límites del problema planteado

\footnotetext{
¿Qué son las muchas (versiones) de La Ilíada de Chapman a Magnien sino diversas perspectivas de un hecho móvil, sino un largo sorteo experimental de omisiones y de énfasis. (No hay esencial necesidad de cambiar de idioma, ese deliberado juego de la atención no es imposible dentro de una misma literatura.) Presuponer que toda recombinación de elementos es obligatoriamente inferior a su original, es presuponer que el borrador 9 es obligatoriamente inferior al borrador 11(sic) -ya que no puede haber sino borradores. El concepto de texto definitivo no corresponde sino a la religión o al cansancio (1980: 181).
}

Analicemos al detalle la riqueza conceptual que propone esta cita. Una idea principal salta a la vista: su negativa de aceptar la posibilidad de que exista un texto original, definitivo y superior a los otros. La creencia en un texto definitivo es un acto de fe, que al igual que la religión, funciona como elemento estabilizador. La fe tranquiliza o adormece la inquietud del pensamiento, es un freno para la proliferación de los sentidos. La Ilíada de Homero es, según Borges, un hecho móvil, que los diversos traductores (¿lectores?) pondrán en movimiento gracias a un proceso de lectura que funciona a partir de omisiones y énfasis. Pero Borges rebasa el problema de la traducción al plantear que no es necesario cambiar de idioma para que acontezca ese deliberado juego de la atención.

No puedo dejar de pensar en Barthes al leer a Borges. No olvidemos la insistencia con que el teórico francés combatía este mismo presupuesto -el de la existencia de un texto definitivo- relacionándolo también con el problema de la lectura. Para Barthes no existe una verdad oculta en el texto que sancione su validez y que, por lo tanto, los lectores deban descubrir. El sentido de una escritura viene dado por el choque entre el lector y el texto -entendido como campo metodológico- y presuponer un texto definitivo es hacer una lectura teológica

Hoy en día sabemos que un texto no está constituido por una fila de palabras, de las que se desprende un sentido único, teológico, en cierto modo (pues sería el mensaje del Autor-Dios), sino por un espacio de múltiples dimensiones en el que se concuerdan y se contrastan diversas escrituras, ninguna de las cuales es la original: el texto es un tejido de citas provenientes de los mil focos de la cultura (Barthes 1994: 69).

La unidad de un texto no está en su origen sino en su destino, lo cual implica un desplazamiento del autor al lector o, como dice Barthes (1994: 71), "el nacimiento del lector se paga con la muerte del autor". 
El problema de la lectura, y, más aún, el papel del lector (que habían estado ausentes de la teoría literaria tradicional) son de esta forma ubicados por Barthes en el centro de las problematizaciones del postestructuralismo. La lucidez de Borges en este tema también constituye motivo de asombro. Ya en el prólogo de su primer libro de poemas Fervor de Buenos Aires, publicado en 1923, declara lo siguiente: "Nuestras nadas poco difieren; es trivial y fortuita la circunstancia de que seas tú el lector de estos ejercicios, y yo su redactor". Llamo la atención sobre los términos utilizados ya que Borges denomina a sus poemas ejercicios y se considera a sí mismo redactor, desacralizando así el papel del autor y la noción de obra.

Pero la lectura, ya sea como tema, ya sea como motor de la escritura, constituye, además, una de las preocupaciones recurrentes en la reflexión de Borges. En el prólogo a Historia Universal de la Infamia, su primera incursión en el campo de la ficción, éste parece tener claro que la escritura proviene de la lectura o, más aún, que la materia de la literatura (más allá o más acá de la realidad o de lo que se supone que este concepto significa) es la literatura misma

\footnotetext{
Los ejercicios de prosa narrativa que integran este libro fueron ejecutados de 1933 a 1934. Derivan, creo, de mis relecturas de Stevenson y de Chesterton y aun de los primeros filmes de Von Sternberg y tal vez de cierta biografía de Evaristo Carriego (1980: 241).
}

Casi cuarenta años después Barthes dirá que leer es escribir fundiendo la escritura y la lectura en una misma práctica.

En Borges, la lectura y la escritura son las prácticas que le permiten vincularse amorosamente con el lenguaje. Simétricamente, ambas son prácticas que incluyen el silencio. Hay una anécdota que bien nos sirve como métafora de lo que quiero plantear. Según Adolfo Castañón:

\footnotetext{
Una vez fueron Borges y María Kodama a recibir algún premio -según contó alguna vez Aurora Bernárdez-, la devota y brillante traductora de Calvino al castellano- y se encontraron a Italo Calvino y a su mujer. Esta saludó cariñosamente al escritor argentino y a su amiga. De pronto Borges preguntó: ¿Y Calvino, cómo está? Bien maestro, aquí estoy, mucho gusto, dijo el novelista italiano. Sí, dijo Borges, ya lo sabía. Lo reconocí por su silencio (1999: 43).
}

Esta historia ilustra un rasgo distintivo de la estrategia de lectura de Borges, quien no sólo sabía poner en movimiento los textos, recrearlos, sino que se empeñaba en leer sus silencios. Para Borges era tan importante lo que un escrito decía como lo que callaba. Sus lecturas generalmente violentan los textos, descentran las ideas importantes y privilegian los aspectos marginales.

También su escritura está sostenida por un fondo de silencio. Su estilo alusivo e indirecto, lacunar, fragmentario, contrario al énfasis, parece abrir un mundo de posibilidades en cada frase nueva. El mismo Borges decía que sus cuentos "estaban escritos como si no se comprendieran totalmente los hechos", para dejar un amplio margen de juego a su lector. Efectivamente esta poética del silencio exige una actitud especial del lector que no puede conformarse con lo evidente. Se trata de un lector en cierta forma emparentado con el psicoanalista, empeñado en escuchar los silencios, en hacerle caso a los pensamientos carentes de importancia, atento a las fallas y los desvanecimientos del texto.

Por otra parte en Borges, quizás como consecuencia del papel asignado a la lectura, la figura del autor aparece de forma inevitablemente disminuida. Como apunta Ana María Barrenechea: 
Muy a menudo dedica sus ensayos a destacar lo que ciertos escritores creyeron ser y lo que en realidad fueron: es decir que los elige como símbolos de la ceguera y el desamparo humanos... (1984: 56).

La ceguera y el desamparo humanos son inseparables de otro concepto que brilla en su texto: una manera de pensar el lenguaje radicalmente subversiva para la teoría literaria de la época. En Borges el lenguaje no es un instrumento neutral y exterior al autor, por el contrario, puede ser la fuente misma de la escritura, incluso de espaldas al autor. Cito de nuevo "Las versiones homéricas":

\footnotetext{
Doy sin entusiasmo estas conjeturas; lo único cierto es la imposibilidad de apartar lo que pertenece al escritor de lo que pertenece al lenguaje. Cuando leemos en Agustín Moreto:

Pues en casa tan compuestas

¿Qué hacen todo el santo día?

Sabemos que la santidad de ese día es ocurrencia del idioma español y no del escritor (1980: 183)
}

Quiero destacar un detalle. El uso de la preposición en antepuesta al nombre del autor en la oración: Cuando leemos en Agustín Moreto, parece indicar que para Borges el texto es un lugar, idea que luego trabajará Barthes ampliamente. Pero lo principal de la cita anterior es que el lenguaje no aparece como un utensilio dócil, que se pliega a la intención de un autor. Borges parece sugerir que el lenguaje se escapa de algún modo a los propósitos del escritor. El lenguaje habla más allá, o incluso, a pesar, del escritor.

Este pesimismo con que plantea la relación del sujeto con el lenguaje lo acompañará a lo largo de toda su escritura. Ejemplo casi melancólico se encuentra en El Hacedor. Lo cito por la particularidad de que se refiere a él mismo:

\section{Nada me cuesta confesar que he logrado ciertas páginas válidas, pero esas páginas no me pueden salvar, quizá porque lo bueno ya no es de nadie, ni siquiera del otro, sino del lenguaje o la tradición (1960: 50).}

Esta fineza conceptual con que Borges reflexiona el problema del lenguaje no es ajena a sus lecturas filosóficas, todo lo contrario. Ya desde Inquisiciones, su primer libro de ensayos, publicado en 1925, Borges denuncia las trampas que el lenguaje tiende al pensamiento filosófico, condenado a su mediación. Por otra parte, en "El idioma de los argentinos", artículo también publicado en 1925, se expresa de la siguiente forma:

\footnotetext{
Que la resignación -virtud a que debemos resignarnos- sea con nosotros. Ella será nuestro destino: hacernos a la sintaxis, a su concatenación traicionera, a la imprecisión, a los talveces, a los demasiados énfasis, a los peros, al hemisferio de mentira y de sombra de nuestro decir [citado por Barrenechea 1984: 64].
}

La visión desmitificadora del lenguaje es un pilar fundamental también para los pensadores postestructuralistas. Barthes dirá que es imposible escapar al lenguaje -entendido como ley- y su propuesta es hacerle trampas a la lengua. Por su parte, Borges, no sin ironía, propone la virtud cristiana de la resignación, aunque, paradójicamente, en su escritura tramposa parece poner en práctica el consejo de Barthes.

Resulta imposible no vincular la forma en que Borges piensa el lenguaje, el ser humano y la relación entre la realidad y la ficción, con sus lecturas tempranas e insistentes de Schopenhauer, Nietzsche, Berkeley. Es como si Borges hubiera construido un punto de partida epistemológico que le permitiera jugar, inventar, escribir, cual niño travieso y despreocupado que no pretende hacer ni ciencia ni filosofía. Quizá porque desconfía de la vanidad de ambas prácticas. Se trata, más bien, de un escepticismo radical en cuanto al problema de la verdad. Esto explicaría su afirmación de que lo atraen las ideas filosóficas por su valor estético y no por la verdad que encierran. Como afirma Ana María Barrenechea: 
(En Borges)... Hay el amargo convencimiento de que el universo, el destino del hombre dentro del universo son inexplicables, y de que cualquier utensilio humano -pensamiento, lenguaje, construcciones filósoficas- es inadecuado para aprehenderlos (1984: 61).

Esta "epistemología" borgeana no sólo es condición de posibilidad de sus ensayos sino que también construye y estructura sus cuentos. Es más, quizá se encuentra en la base de ciertos escritos suyos que tienden a borrar las fronteras entre el ensayo y la ficción, convirtiendo a la ficción y la realidad en dos mundos intercambiables, en dos entes que no guardan una relación de jerarquía.

La escritura de Borges insiste en confundir y equiparar los espacios de la ficción y la realidad. En sus textos, los límites entre realidad y ficción, cuando aparecen, son siempre precarios, difusos. Lo más asombroso es que el lector no puede sustraerse a este efecto. Las citas apócrifas o tergiversadas, los comentarios de textos inexistentes pero posibles, producen inestabilidad en el lector inocente y también en el avezado. Cuentan los biógrafos que más de un crítico serio, estimulado por una referencia de Borges, se permitió solicitar un libro inexistente a su bibliotecario. El lector borgeano deberá, entonces, soportar la incertidumbre de no saber casi nunca cuál es su lugar, su estatuto, pues Borges le sugiere constantemente su posible condición de ente imaginario, ya que los seres reales quizá no son más que sartas de palabras.

\section{Un nuevo lector}

Me atrevo a formular la hipótesis de que quizá uno de los mayores efectos del texto borgeano haya sido la producción de ese nuevo lector que el escritor invocaba ya desde sus primeros ensayos de Discusión. Ese lector que no teme perderse en la contradicción, que se enreda en las lenguas infinitas del texto, que duda de la consistencia de su ser y de la verdad, ese contrahéroe (como dice Barthes) que encuentra momentáneamente en el texto su placer.

Este nuevo lector, hijo del amor apasionado de Borges por la filosofía, engendrado en esa zona turbulenta donde la literatura y el pensamiento filosófico se tocan fugazmente, vendrá a dislocar el orden jerárquico de los textos y los saberes. Esta nueva forma de leer es la que quizá posibilita pensar de otro modo. El poeta filósofo ha abierto el camino al filósofo poeta. Es tiempo de volver sobre la pregunta que dejamos en el aire en relación con la lectura que hace Foucault de Borges. No olvidemos que Deleuze dice que "el pensamiento de Foucault es poético precisamente en virtud de su específica relación con la verdad". A lo cual Foucault contesta unas líneas más adelante:

\footnotetext{
En cuanto al problema de la ficción, es para mí un problema muy importante; me doy cuenta de que no he escrito más que ficciones. No quiero, sin embargo, decir que esté fuera de la verdad. Me parece que existe la posibilidad de hacer funcionar la ficción en la verdad; de inducir efectos de verdad con un discurso de ficción, y hacer de tal suerte que el discurso de verdad suscite, "fabrique" algo que no existe todavía, es decir "ficcione" (Deleuze 1987: 14).
}

El trayecto circular entre literatura y filosofía es transitado a la inversa y Borges enfrenta a su lector filósofo ante un espejo deformado de su propio discurso. Acaso no sea necesario recurrir a la ficción para pensar el problema de la verdad y el saber. Es quizá Borges quien sutilmente murmura al oído de Foucault y le señala los límites del pensamiento y la necesidad de "ficcionar" para producir ese chispazo, ese centelleo que los seres humanos de todos los tiempos se empeñan en apresar bajo el nombre de verdad. Para finalizar, quisiera compartir con ustedes una cita enigmática de Borges que me ha inquietado por mucho tiempo. 
Es el párrafo que cierra su cuento "La muralla y los libros":

La música, los estados de felicidad, la mitología, las caras trabajadas por el tiempo, ciertos crepúsculos y ciertos lugares, quieren decirnos algo, o algo dijeron que no hubiéramos debido perder. O están por decir algo; esta inminencia de una revelación, que no se produce, es, quizá, el hecho estético (1980: 133).

¿Será posible que esta manera borgeana de pensar el hecho estético, como ese momento en que algo se pierde y algo está por suceder, pueda iluminarnos sobre el problema de la verdad?

Ahora intuyo que la frase de Borges inquieta radicalmente pues va más allá de ese lugar común que fatiga nuestro lenguaje y nuestro cómodo imaginario teórico, a saber, la idea de que no hay verdades absolutas. Borges lúcidamente se adelanta al relativismo y nos invita, una vez más, a practicar la lectura en silencio para poder meditar. ¿Y si la verdad fuera también de algún modo esta inminencia de una revelación que no se produce?

\section{Notas}

1. La noción de importar es sugerida por Jacques Lacan en su Seminario Les non-dupes errent. Clase del 9-4-74. Este concepto es trabajado ampliamente por Roberto Harari en Polifonías del arte en psicoanálisis, libro consignado en la bibliografía.

2. Para efectos expositivos utilizo el término postestructuralismo, aunque estoy consciente de la imprecisión a la que puede inducir su uso pues como plantea Culler (1988: 34): "Lo que generalmente se designa mediante ese término es un cuerpo amorfo de teoría y de crítica. Podría hablar más sobre los modos en que el término induce a error, pero a pesar de eso, todavía está aquí; la gente lo usa; y el que yo hable sobre su inexactitud no hará que se vaya".

\section{Bibliografía}

Barrenechea, Ana María. 1984. La expresión de la irrealidad en la obra de Borges. Buenos Aires: Bibliotecas Universitarias.

Barthes, Roland.1986. El placer del texto. México: Siglo XXI Editores.

1994. "La muerte del autor”. En: El Susurro del lenguaje. Barcelona: Paidós.

Borges, Jorge Luis. 1960. Obras Completas. Buenos Aires: Emecé.

1980. Prosa Completa. Barcelona Bruguera.

1993. Siete Noches. México: Fondo de Cultura Económica.

1999. Prólogo con un prólogo de prólogos. Buenos Aires: Emecé.

Castañón, Adolfo.1999. “Cuarta de Borges”. En: Ocho ensayos sobre Borges. México: Cruz O.

Culler, Jonathan. 1987-1988. "La crítica postestructuralista”. En: Criterios, No. 21-24. La Habana: Casa de las Américas. 
Deleuze, Gilles. 1987. Foucault. Barcelona: Paidós.

Foucault, Michel. 1984. Las palabras y las cosas. Barcelona: Planeta-Agostini.

Harari, Roberto. 1998. Polifonías del arte en psicoanálisis. Barcelona: Ediciones del Serbal.

Manzor Coats, Lillian. 1996. Borges-Escher/Sarduy-Cobra: Un encuentro posmoderno. Madrid: Pliegos.

Nuño, Juan. 1986. La filosofía de Borges. México: Fondo de Cultura Económica.

Olea, Rafael. 1993. El otro Borges. El primer Borges. Buenos Aires: Fondo de Cultura Económica.

Vázquez, María Esther. 1996. Borges. Esplendor y Derrota. Barcelona: Tusquets. 